\title{
Cumulative visual impact of two coagulability disorders: A case report
}

\author{
HORIA T. STANCA ${ }^{1}$, BOGDANA TĂBĂCARU ${ }^{1}$, FLORIAN BALT $\breve{~}^{1}$, MONICA MĂLĂESCU ${ }^{2}$, \\ SIMONA STANCA ${ }^{3}$, MIHNEA MUNTEANU ${ }^{4}$, DIANA-MARIA DĂRĂBUȘ ${ }^{4}$, \\ COSMIN ROȘCA ${ }^{5}$ and ADRIAN COSMIN TEODORU ${ }^{2}$ \\ ${ }^{1}$ Department of Ophthalmology, 'Carol Davila' University of Medicine and Pharmacy, 050474 Bucharest; \\ ${ }^{2}$ Department of Ophthalmology, Faculty of Medicine, 'Lucian Blaga' University, 550159 Sibiu; \\ ${ }^{3}$ Department of Pediatrics, 'Carol Davila' University of Medicine and Pharmacy, 050474 Bucharest; \\ ${ }^{4}$ Department of Ophthalmology, 'Victor Babeș' University of Medicine and Pharmacy, 300041 Timisoara; \\ ${ }^{5}$ Department of Ophthalmology, Oculens Clinic, 400501 Cluj-Napoca, Romania
}

Received September 4, 2020; Accepted October 5, 2020

DOI: $10.3892 / \mathrm{etm} .2020 .9348$

\begin{abstract}
Cumulative visual impact of two coagulability disorders were reviewed by presenting a case of a young female patient with a spontaneous abortion and two thromboembolic events in 8 years, whose visual function was severely affected. The particularities of her genetic constellation regarding the retinal circulation are also discussed. The patient developed a central retinal artery occlusion in the right eye during pregnancy in 2010, which led to an extended hematological workup that revealed presence of MTHFR C677T and MTHFR A1298C heterozygote mutations. The screening for myeloproliferative disorders showed JAK2 V617F gene mutation. Test results confirmed the diagnosis of thrombophilia and essential thrombocythemia and she was recommended permanent treatment with low molecular weight heparin, platelet antiaggregant, peripheral vasodilator and neuroprotectors. Despite the treatment, the patient developed central retinal vein occlusion in the fellow eye 8 years after the first thromboembolic event. The visual acuity for the right eye $(0.9 \log$ MAR) remained poor and the visual acuity for the left eye recovered completely (from $0.3 \log$ MAR to $0 \log$ MAR). However, new retinal artery or vein occlusions could occur in the future and there is also a
\end{abstract}

Correspondence to: Dr Simona Stanca, Department of Pediatrics, 'Carol Davila' University of Medicine and Pharmacy, 8 Eroilor Sanitari Street, 050474 Bucharest, Romania

E-mail: simonastanca@yahoo.com

Dr Monica Mălăescu, Department of Ophtalmology, Faculty of Medicine, 'Lucian Blaga' University, Victoriei 10, 550159 Sibiu, Romania

E-mail: monica_ilovici@yahoo.com

Key words: central retinal vein occlusion, papillophlebitis, central retinal vein occlusion, central retinal artery occlusion, coagulation, thrombophilia, essential thrombocythemia risk of thrombosis in other areas, such as cerebral, pulmonary or renal, due to the general coagulability imbalance.

\section{Introduction}

Retinal arterial occlusion affects mainly older people, with a mean age of 60 years at presentation. Young patients are affected under specific conditions. Central retinal arterial occlusion presents abrupt, painless loss of vision. Visual acuity is typically reduced to the level of counting fingers or hand movements, unless there is a separate cilioretinal artery supplying the macula (1-4). Relative afferent pupillary defect (RAPD) is present.

There are several causes for central retinal artery occlusion. Emboli are $75 \%$ cholesterolic, $15 \%$ thrombi and $10 \%$ calcific $(1,5,6)$. Thrombosis develops at the site of an atherosclerotic plaque, vasculitic occlusions are associated with inflammatory disorders i.e. Giant cell arteritis, Behcet disease, Polyarteritis nodosa, Wegener's granulomatosis, Systemic Lupus erythematosus, Susac's disease or dermatomyositis, and infectious conditions also cause an inflammatory response in the retina with possible occlusive complications (7-12). Other causes can be medical procedures, such as arterial angiography, vitreoretinal surgery, retrobulbar injections or cervical manipulation (13), structural anomalies, such as pre-papillary arterial loops and optic disk drusen (14) and vasospasm induced by migraines or drug use $(1,15)$. However, the most common causes of central retinal artery occlusion in young patients are coagulation disorders (1).

Retinal vein occlusion is the most frequent primary vascular disorder of the retina. Central retinal vein occlusion takes place at a mean age between 60 and 70 years. About $10 \%$ of the patients are younger than 50 years (16). It is generally monocular, but 5 to $11 \%$ of patients will suffer from occlusion in the contralateral eye within five years (17).

Symptoms include floaters, black spots or metamorphopsia, as well as blurred vision, which may occur after getting up in the morning and fade during the day. The visual acuity might deteriorate over a couple of days, leading the patient to visit an 
ophthalmology clinic only after 1-3 weeks have passed (18). The patient usually presents with a visual acuity of 0.1-0.5.

Risk factors for central retinal vein occlusion may be cardiovascular, local (trauma, retinal vasculitis, glaucoma, optic disk drusen), coagulation disorders and hyperviscosity syndromes (16).

Thrombophilia refers to a diverse group of disorders that predispose an individual to the development of thrombosis. Congenital thrombophilic states are inherited disorders, which result in disturbance of the coagulation system either through increased levels of procoagulants, deficiencies of anticoagulants or reduced fibrinolysis (1,19-21). Acquired causes of thrombophilia include a diverse group of conditions. In the antiphospholipid syndrome autoantibodies (22) to phospholipids form immune complexes resulting in thrombosis formation. Hyperhomocysteinemia leads to the damage of the vascular endothelium promoting thrombus formation $(23,24)$. Other associations with retinal arterial and venous occlusion include hyperviscosity states, such as myeloproliferative disorders, and pregnancy $(1,16)$.

\section{Case report}

A 32-year old pregnant female patient was admitted in another clinic in 2010 for sudden decrease of visual acuity in the right eye, with no apparent precipitating factors. The patient had no relevant family history or ophthalmological afflictions, but she suffered from a spontaneous abortion at three weeks, one year prior to this event, followed by a normal pregnancy. At presentation, her best corrected visual acuity was 20/30 (0.2 logMAR) for the right eye and 20/20 (0 logMAR) for the left eye with no correction. The intraocular pressure by Goldmann applanation tonometry (GAT) was $17 \mathrm{mmHg}$ in the right eye and $18 \mathrm{mmHg}$ in the left eye. After external examination, slit-lamp examination of the anterior and posterior segment and paraclinical investigations, she was diagnosed with central retinal artery occlusion in the right eye and was recommended to undergo a hematological examination. The perimetric exam revealed a central scotoma in the right eye.

The following paraclinical examination (Table I) revealed mildly higher RDW and PDW and lower platelet number $(\sim 60,000 / \mathrm{mcl})$. However, it is known that platelet values can decrease during pregnancy without pathological significance. Later, the platelet count returned to pseudo normal values $(489,000 / \mathrm{mcl})$, which fluctuated over time. Considering this, she was recommended permanent treatment with low molecular weight heparin, platelet antiaggregant, peripheral vasodilator, neuroprotectors and screening for clotting disorders.

Regarding the tests for hereditary thrombophilia, Antithrombin (AT), Activated Protein C Resistance (APCR), Factor V Leiden (FVL), Protein C were normal. Prothrombin gene mutation (PGM) was absent and Protein $\mathrm{S}$ was only slightly lower. The coagulogram (APTT, PT, Fibrinogen, ESR) was normal. However, homocysteine levels were slightly risen. Antibodies associated with acquired thrombophilia (Anti-phospholipidic antibodies, Lupic anticoagulant, Anti-cardiolipin antibodies, Beta 2 glicoprotein-1 antibodies) were absent.

Most antigens present in autoimmune disorders were negative (HLAB27, RNP/Sm, Sm, SS-A, RO-52, SS-B, Scl-70,
PM-Scl100, JO-1, CB, PCNA, dSDNA, NUC, RIB). AMA-M2 test result was uncertain and DFS70, a type of anti-nuclear antigen, was strongly positive.

Additional investigations (Table II) showed normal blood pressure, normal cerebral MRI, normal dental exam. The screening for Paroxysmal Nocturnal Hemoglobinuria by immunophenotyping (GPI deficit, PNH clone) was negative. However, the screening for mutations of genes that control homocysteine metabolism revealed MTHFR C677T and MTHFR A1298C heterozygote mutations, associated with a high risk of spontaneous abortions, congenital malformations and thromboembolic evens (25-28). The patient was diagnosed with thrombophilia.

The screening for myeloproliferative disorders showed a normal abdominal echography, with a normal sized spleen, absence of FAL and c-MPL mutation (W515L, W515K, SN505N), and presence of JAK2 V617F gene mutation. This mutation is associated with Polycythemia vera (PV), Idiopathic myelofibrosis (IMF) and Essential thrombocythemia (ET).

PV is characterized by an increase in red cells, white cells and platelets. The patients have a plethoric appearance, pruritus and splenomegaly. Complications include hemorrhage and thromboembolic events and they can progress to myelofibrosis and acute leukemia (29). ET is characterized by an increased platelet count. In most cases, it is clinically asymptomatic, but it can manifest with thromboembolic events that may lead to disease detection (29). IMF is defined by splenomegaly, bone marrow fibrosis and a leukoerythroblastic blood picture that includes anaemia, thrombocythemia or thrombocytopenia and variable white cell counts. The disease usually progresses to transfusion dependent anaemia, symptomatic splenomegaly and transformation to acute leukemia (29).

Considering these aspects, essential thrombocythemia was the most likely diagnosis. For confirmation, a medullar biopsy was needed, which was positive.

Two years later, in 2012, the patient requested a routine check-up in our clinic, and the visual acuity of the right eye had decreased to 20/160 (0.9 logMAR). The optical coherence tomography (OCT) of the right macula showed severe macular atrophy (Fig. 1).

In 2018,8 years after the arterial occlusion, the patient was admitted again to our clinic for sudden decrease of visual acuity in the left eye. At presentation, her best corrected visual acuity was 20/160 (0.9 logMAR) for the right eye and 20/40 (0.3 $\log$ MAR) for the left eye without correction. The intraocular pressure by GAT was $16 \mathrm{mmHg}$ in the right eye and $13 \mathrm{mmHg}$ in the left eye.

External examination and slit-lamp examination of the anterior segment revealed no abnormal findings. Relative afferent pupillary defect was absent.

The fundus of each eye was examined after pharmaceutical mydriasis with $0.5 \%$ tropicamide and $10 \%$ phenylephrine hydrochloride ophthalmic solutions. The right eye had a pallid papilla in the temporal half, spastic arteries, moderately dilated veins and no foveolar reflex. The left eye had a protruding, hyperemic papilla, with imprecise delimited margins, turgescent veins, cotton wool spots and intraretinal haemorrhages concentrated around the papilla (Fig. 2).

Perimetry was assessed by the Humphrey Visual Field Analyzer, central 24-2 threshold program, with a size III white 
Table I. Paraclinical investigations.

Hereditary thrombophilia

\begin{tabular}{ll}
\hline Tests & \\
\hline C Protein & Results \\
S Protein & Slightly $\downarrow-46.58 \%(\mathrm{~N}: 54.7-123.7 \%)$ \\
Antithrombin & Normal \\
Activated protein C resistance & Normal \\
Factor V leiden & Normal \\
Prothrombin gene nutation & Absent \\
Homocysteine & Slightly $\uparrow-17 \mu \mathrm{mol} / \mathrm{l}(\mathrm{N}: 12-15 \mu \mathrm{mol} / \mathrm{l})$ \\
Coagulogram (APTT, PT, fibrinogen, ESR) & Normal \\
\hline
\end{tabular}

Acquired thrombophilia

\begin{tabular}{ll}
\hline Tests & Results \\
\hline Anti-phospholipidic antibodies & Negative \\
Lupus anticoagulant (LAC) & Negative \\
Anti-cardiolipin antibodies (ACL) & Negative \\
Beta 2 glicoprotein-1 antibodies & Negative \\
\hline
\end{tabular}

Autoimmune disorders

\begin{tabular}{ll}
\hline Tests & Results \\
\hline Antibodies: RNP/Sm, Sm, SS-A, RO-52, SS-B, Scl-70, PM-Scl100, JO-1, CB, & Negative \\
PCNA, dSDNA, NUC, RIB & \\
HLAB27 & Negative \\
AMA-M2 & Class +: Inconclusive \\
DFS70 & Class +++: Highly positive \\
\hline
\end{tabular}

stimulus. Reliability indices were very good in visual fields for both eyes. It demonstrated centrocecal scotoma with inferonasal extension for the right eye and superior arcuate scotoma for the left eye (Fig. 3).

Optical coherence tomography (OCT) of the optic nerve showed temporal atrophy of the retinal nerve fiber layer (RNFL) in the right eye and thickening of the nerve fiber layer for $360^{\circ}$ around the optic disc in the left eye, secondary to the papillary edema (Fig. 4). The macular cube analysis revealed severe atrophy of the right macula and subretinal fluid in the interpapillo-macular region of the left eye (Fig. 5).

Based on this clinical and paraclinical investigations, we established the working diagnosis of Papillophlebitis. The patient was further investigated in order to establish the course of treatment. We recommended maintaining the treatment with low molecular weight heparin, platelet antiaggregant, peripheral vasodilator, neuroprotectors and regular hematological check-ups.

The differential diagnosis (Table III) included causes of papillary edema associated with cotton wool spots and retinal hemorrhages. Diabetic retinopathy, hypertensive retinopathy and infections, which can combine all three signs (papillary edema, hemorrhages and exudates) were excluded considering the normal glucose levels, blood pressure and inflammatory markers. Other causes of retinal hemorrhage and exudates, like ocular ischemic syndrome, were also excluded $(1,16,18,30,31)$.

Central retinal vein occlusion occurs in patients over 50 years of age or under 50 with coagulation disorders (16). The decrease in visual acuity is acute, nonprogressive, painless and monocular. Papillary edema is associated with macular edema, retinal hemorrhages in all quadrants, tortuous, dilated veins and cotton wool spots with a characteristic aspect of 'blood and thunder fundus'.

Papillophlebitis is a type of central retinal vein occlusion that occurs in otherwise healthy young people with moderate visual acuity changes with no relative afferent pupillary defect. Papillary edema is predominant and macular edema is rare. Retinal haemorrhages and cotton wool spots are situated mainly peripapillary (16).

Given the above exclusion criteria, the genetic constellation and the fact that the patient presented with several elements common for central retinal vein occlusion, the positive diagnosis included: Thrombophilia with hyperhomocysteinemia, essential thrombocythemia, old central retinal artery occlusion 
Table II. Additional paraclinical investigations.

Additional investigations

\section{Investigation}

Blood pressure

Cerebral MRI

Dental examination

Paroxysmal nocturnal haemoglobinuria (GPI deficit, PNH clone) screening for homocysteine metabolism genes
Results

\author{
Within normal range \\ Normal \\ Normal \\ Negative \\ MTHFR C677T heterozygote mutation \\ MTHFR A1298C heterozygote mutation
}

Screening for myeloproliferative disorders

Investigation

Blood smear

Abdominal echography

FAL

c-MPL mutation (W515L, W515K, SN505N)

JAK2 V617F gene mutation

Medullar biopsy
Results

Inconclusive

Normal spleen

Negative

Absent

Present

Positive for essential thrombocythemia

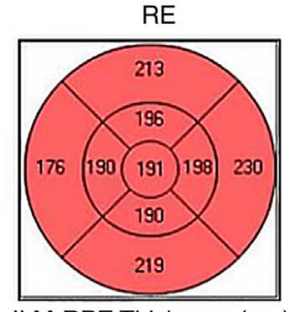

ILM-RPE Thickness ( $\mu \mathrm{m})$
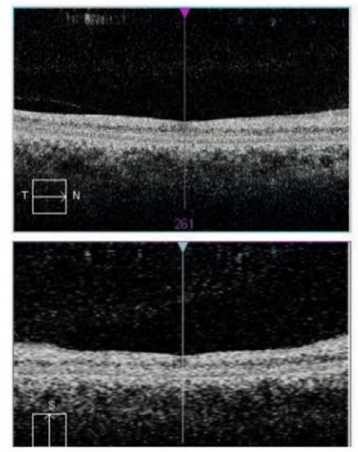

Figure 1. Optical coherence tomography shows macular atrophy in the right eye and normal macular thickness in the left eye.

(CRA) in the right eye and central retinal vein occlusion (CRV) in the left eye.

The patient was followed-up for 2 months. The right eye presented no changes during the follow-up period. For the left eye, best corrected central visual acuity increased from 20/40 (0.3 $\log$ MAR) (in April 2018) to 20/20 (0 $\log$ MAR) (in June 2018). The aspect of the optic disc improved with the remission of the edema (Fig. 6). The cotton wool spots disappeared completely and only a few retinal hemorrhages

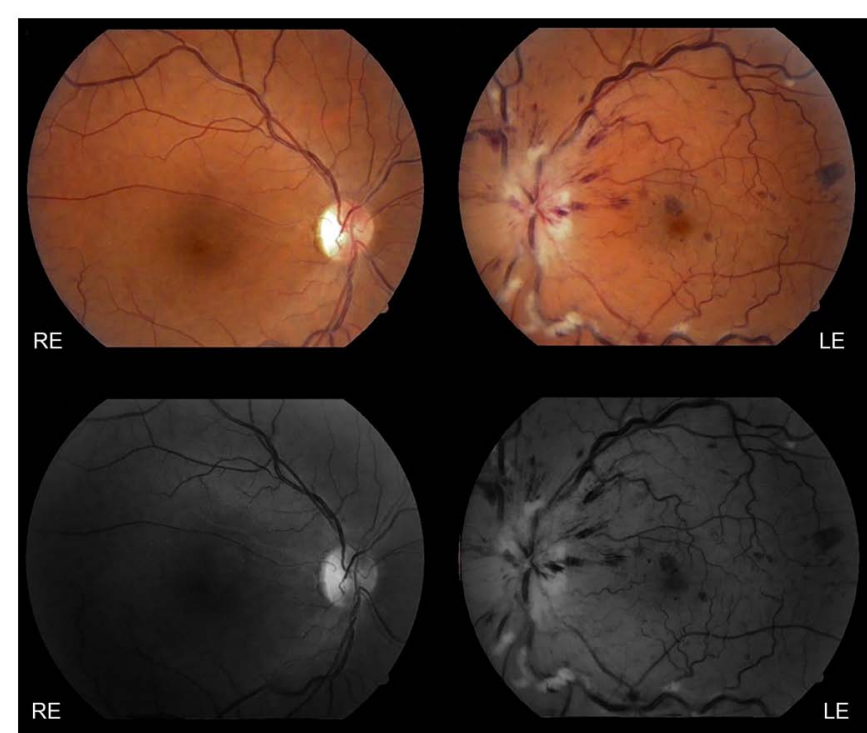

Figure 2. Color and red free fundus photography of the right and left eye.

remained (Fig. 6, black arrows). The caliber of the veins also showed an improvement.

Perimetry was assessed again after 2 months. During the follow-up period there was an improvement of the visual field in the left eye, with significant reduction of the superior arcuate scotoma. The centrocecal scotoma in the right eye remained unchanged (Fig. 7).

The evolution of the optical nerve OCT for the left eye showed partial regression of the papillary edema after 3 weeks, followed at 2 months by total resorption of the papillary edema (Fig. 8). In the right eye, which suffered the central retinal artery occlusion back in 2010, the RNFL atrophy of 
Table III. Differential diagnosis for pathologies overlapping papillary edema, retinal hemorrhages and cotton wool spots.

\begin{tabular}{lll}
\hline Papillary edema & \multicolumn{1}{c}{ Retinal hemorrhages } & Cotton wool spots \\
\hline Central retinal vein occlusion & Central retinal vein occlusion & Central retinal vein occlusion \\
Diabetic retinopathy & Diabetic retinopathy & Diabetic retinopathy \\
Hypertensive retinopathy & Hypertensive retinopathy & Hypertensive retinopathy \\
Infections & Infections & Infections \\
Inflammatory diseases & Inflammatory diseases & Purtscher retinopathy \\
Trauma & Trauma & Radiotherapy \\
NA-AION & Ocular ischemic syndrome & Ocular ischemic syndrome \\
Congenital disk anomalies & Valsalva retinopathy & Siclemy \\
Leber optic neuropathy & Retinal macroaneurysm & Drug reaction (Interferon) \\
Intracranial hypertension & Terson syndrome & Talc emboli \\
Expansive processes & & Metastatic cancer \\
Infiltrative diseases & &
\end{tabular}

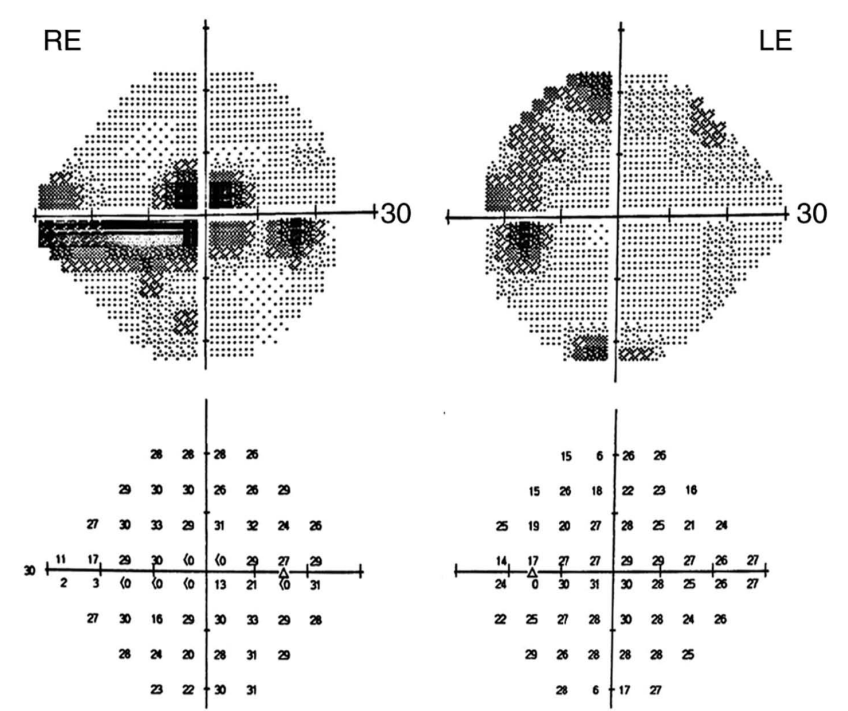

Figure 3. Threshold values maps and grayscale maps from Humphrey visual field of both eyes.

the temporal quadrant and severe macular atrophy persisted. The macula of the left eye regained its normal thickness by subretinal fluid evanescence (Figs. 9 and 10). However, atrophy gradually appeared in the ganglion cell layer, caused by the previous nerve fiber layer inflammation, which hindered the axoplasmic flow and led to the axonal atrophy (Fig. 11).

The best corrected central visual acuity improved progressively in 2 months from 20/40 (0.3 logMAR) to 20/20 (0 $\log$ MAR). The visual field underwent positive changes with the persistence of a small ring-shaped scotoma. The RNFL thickness returned to normal values; however, ganglion cell atrophy was identified by OCT imaging 2 months after the central retinal vein occlusion.

\section{Discussion}

This case is particular because the young patient had two retinal vascular occlusive episodes 8 years apart: The central retinal artery occlusion when she was 32 years old and the central retinal vein occlusion at 40 . The venous occlusion occurred despite being on chronic treatment with low molecular weight heparin, platelet antiaggregant and peripheral vasodilator. She has two genetic defects that predispose to thromboembolic events.

Methylenetetrahydrofolate Reductase (MTHFR) Deficiency is the most common genetic cause of elevated levels of homocysteine in the plasma. The MTHFR enzyme has a role in processing amino acids, specifically, the conversion of homocysteine to methionine. Genetic variations in the MTHFR gene can lead to impaired function or inactivation of this enzyme, which results in mildly elevated levels of homocysteine (25,32-34). Up until recent times, it was believed that MTHFR deficiency led to an increased risk of venous thrombosis, coronary heart disease, and recurrent pregnancy loss, by causing elevated homocysteine levels (25-28). However, more recent studies have not found an association between elevated homocysteine levels and the risk of venous thrombosis or coronary heart disease $(25,35)$.

The myeloproliferative disorders (MPD) are a group of hematological conditions where there is a primary defect at the level of the multi-potent hematopoietic stem cell leading to increased production in one or more blood cell types. The main disorders are polycythemia vera (PV), essential thrombocythemia (ET) and idiopathic myelofibrosis (IMF). ET is characterized by an increased platelet count. In most cases, it is clinically asymptomatic, but it can manifest with thromboembolic events that may lead to disease detection (29).

The JAK2 gene is a member of a family of Janus kinases. It has a role as an upstream signaling molecule directly linked to the erythropoietin receptor. Hematopoietic stem cells from MPD patients are hypersensitive to a range of growth factors and use JAK2 for signaling. The activity of JAK2 is disrupted by the presence of the V617F mutation (29).

The MRC-PT-1 prospective study of ET compared JAK2 V617F mutation positive and negative patients (36). Those with the mutation had features resembling PV, had a higher rate of transformation to PV, higher hemoglobin, neutrophil counts, were more prone to venous thrombosis, but showed lower serum erythropoietin levels and ferritin levels. 


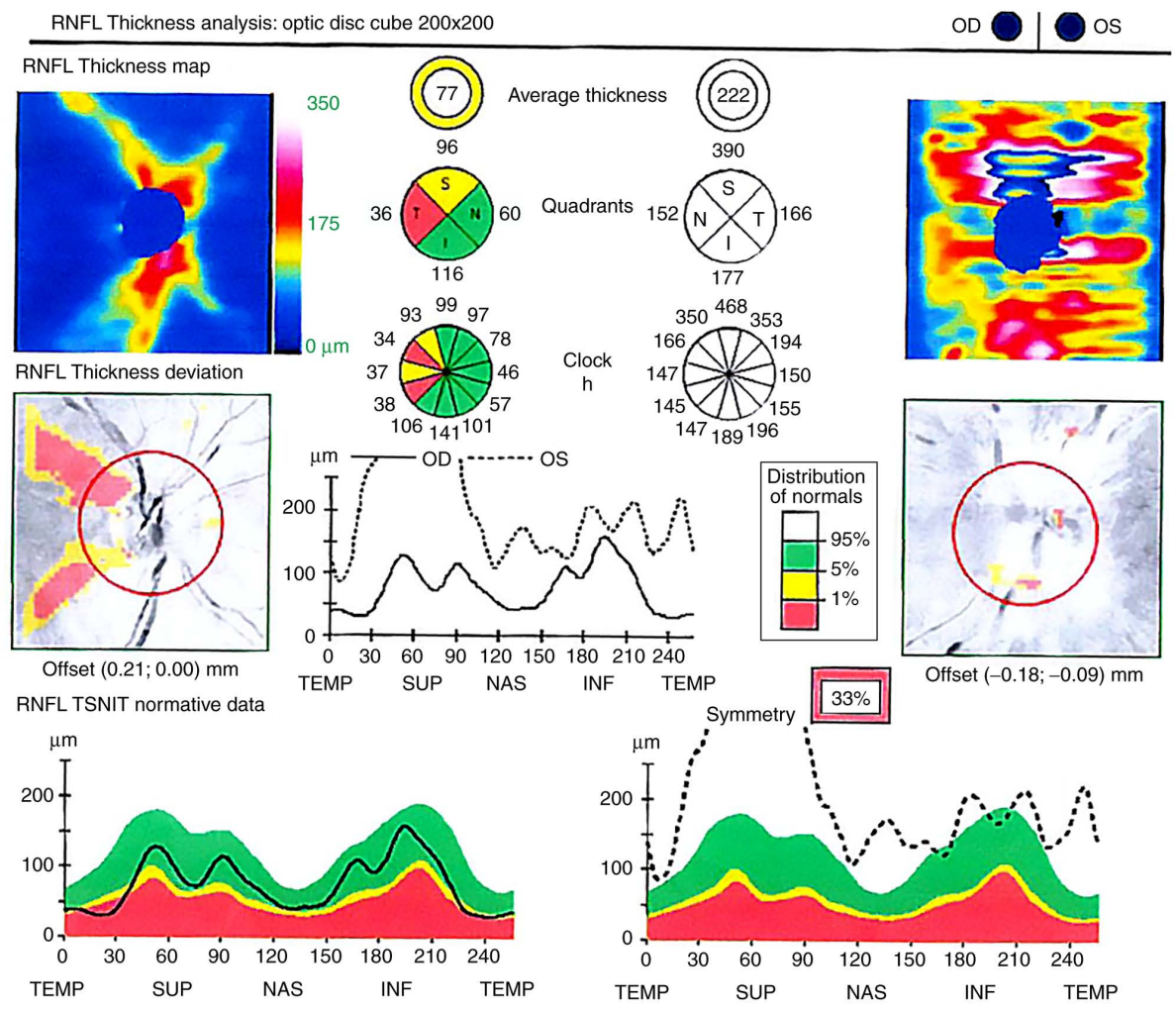

Figure 4. Optical coherence tomography of the optic nerve in both eyes.
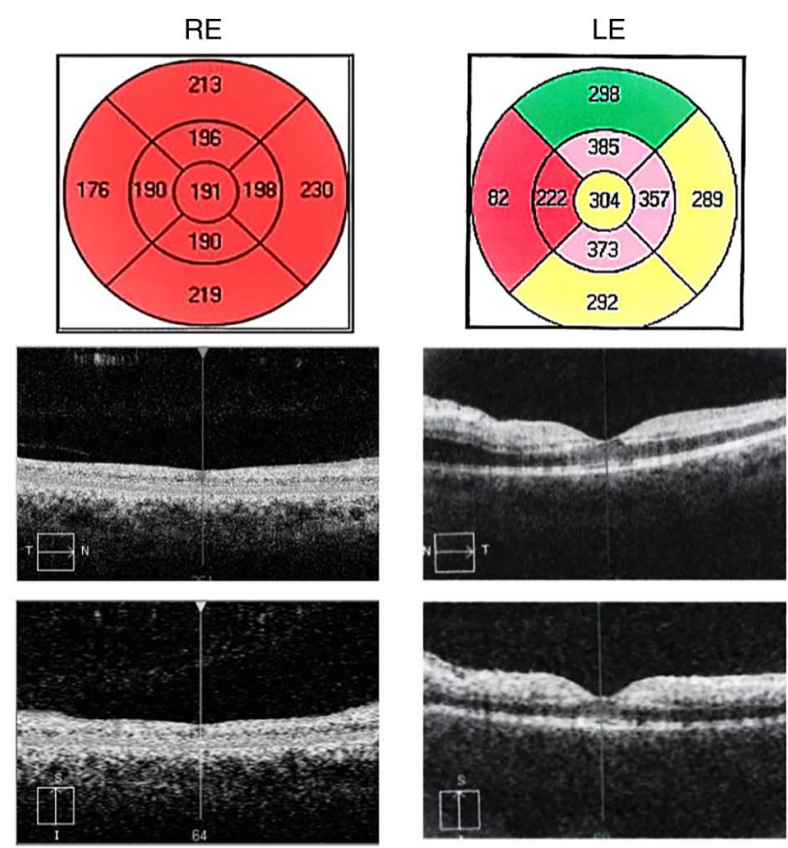

Figure 5. Optical coherence tomography shows macular atrophy in the right eye and subretinal fluid in the left eye.

A factor that might have had an influence on the initial coagulation imbalance, which led to the arterial occlusion, was the fact that the patient was pregnant. Several changes occur to the coagulation system as pregnancy progresses, with the largest changes being seen at term gestation (37-39). While plasma volume increases up to $40 \%$, red blood cell volume increases by only $25 \%$, which leads to a decrease in hemoglobin concentration

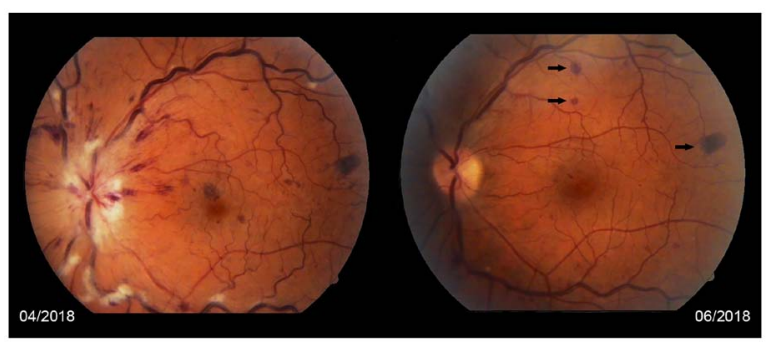

Figure 6. Left eye-remission of the papillary edema, vein turgescence, cotton wool spots and persistence of a few retinal hemorrhages.

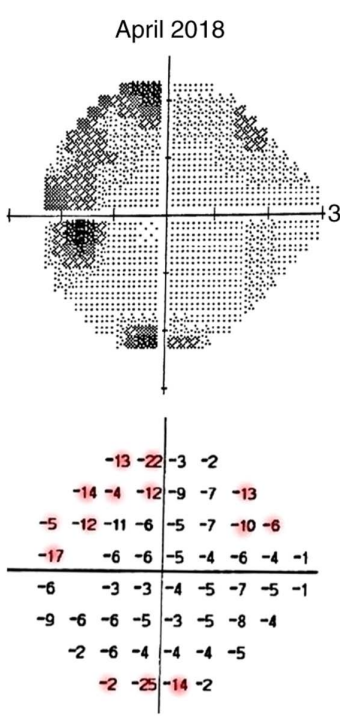

Total deviation
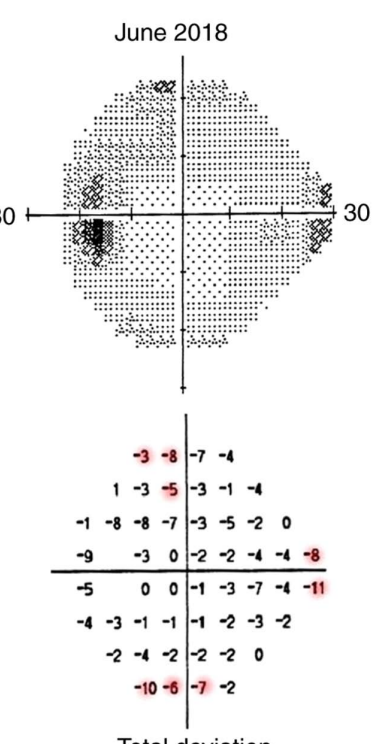

Total deviation
Figure 7. Perimetry evolution in 2 months. 

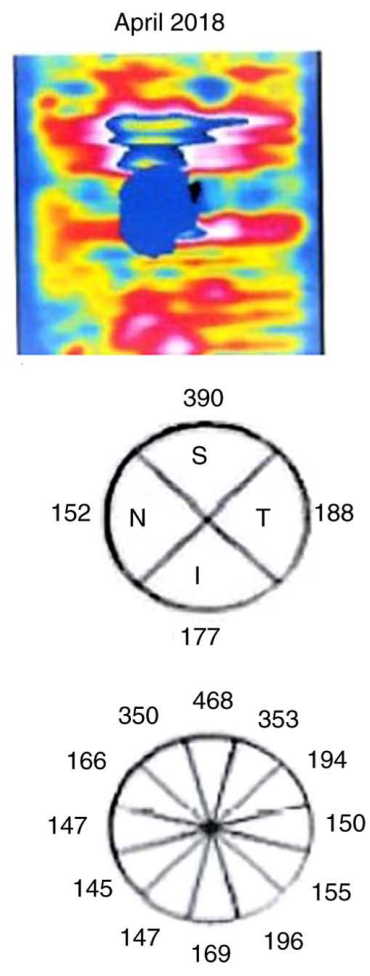

$222 \mu \mathrm{m}$
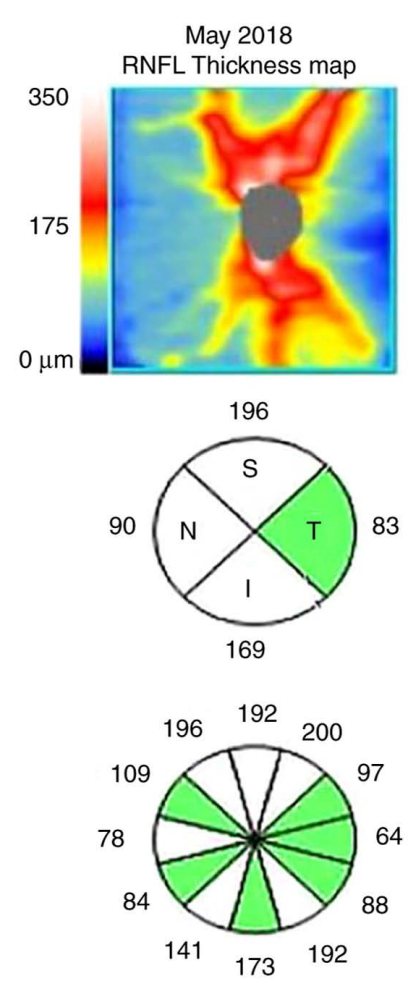

$135 \mu \mathrm{m}$
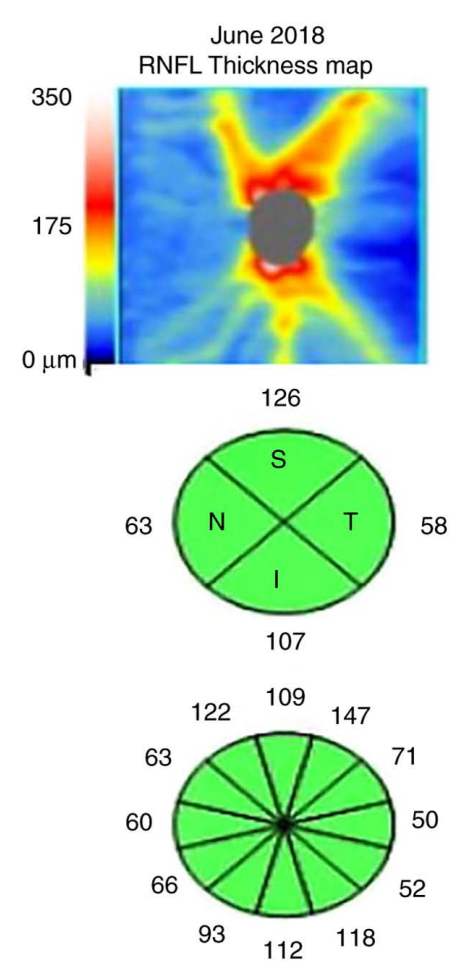

$88 \mu \mathrm{m}$

Figure 8. Optical coherence tomography of the optic nerve in the left eye. Average RNFL thickness: $222 \mu \mathrm{m}$ in April, $135 \mu \mathrm{m}$ in May and $88 \mu \mathrm{m}$ in June.
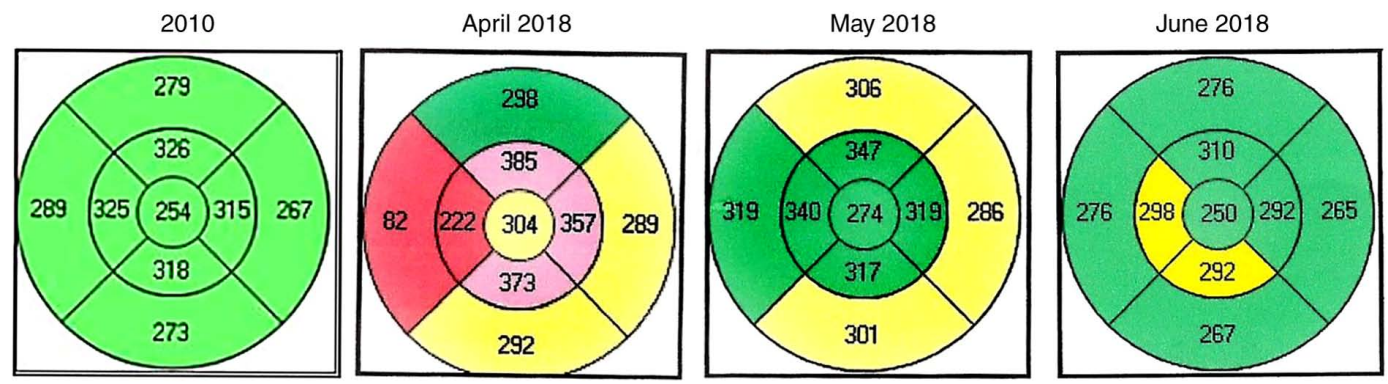

Figure 9. Left eye-Macular OCT evolution. Before and after the central retinal vein occlusion.
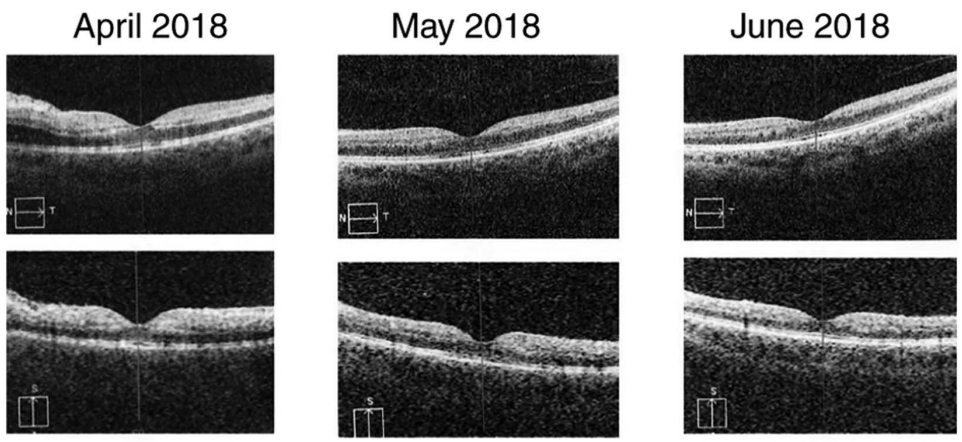

Figure 10. Left eye-Macular OCT evolution. Resorption of the subretinal fluid.

known as the physiological anemia of pregnancy (40). Platelet counts usually decrease, caused by hemodilution and consumption by the uteroplacental unit. However, this decrease is rarely great enough to influence bleeding $(41,42)$.
Coagulation factor concentrations change significantly throughout pregnancy. Factors II, V and protein $\mathrm{C}$ do not change, factor IX is variable, factors VIII, IX, X, XII, VWF and fibrinogen increase more than $100 \%$, D-dimer up to $400 \%$ 


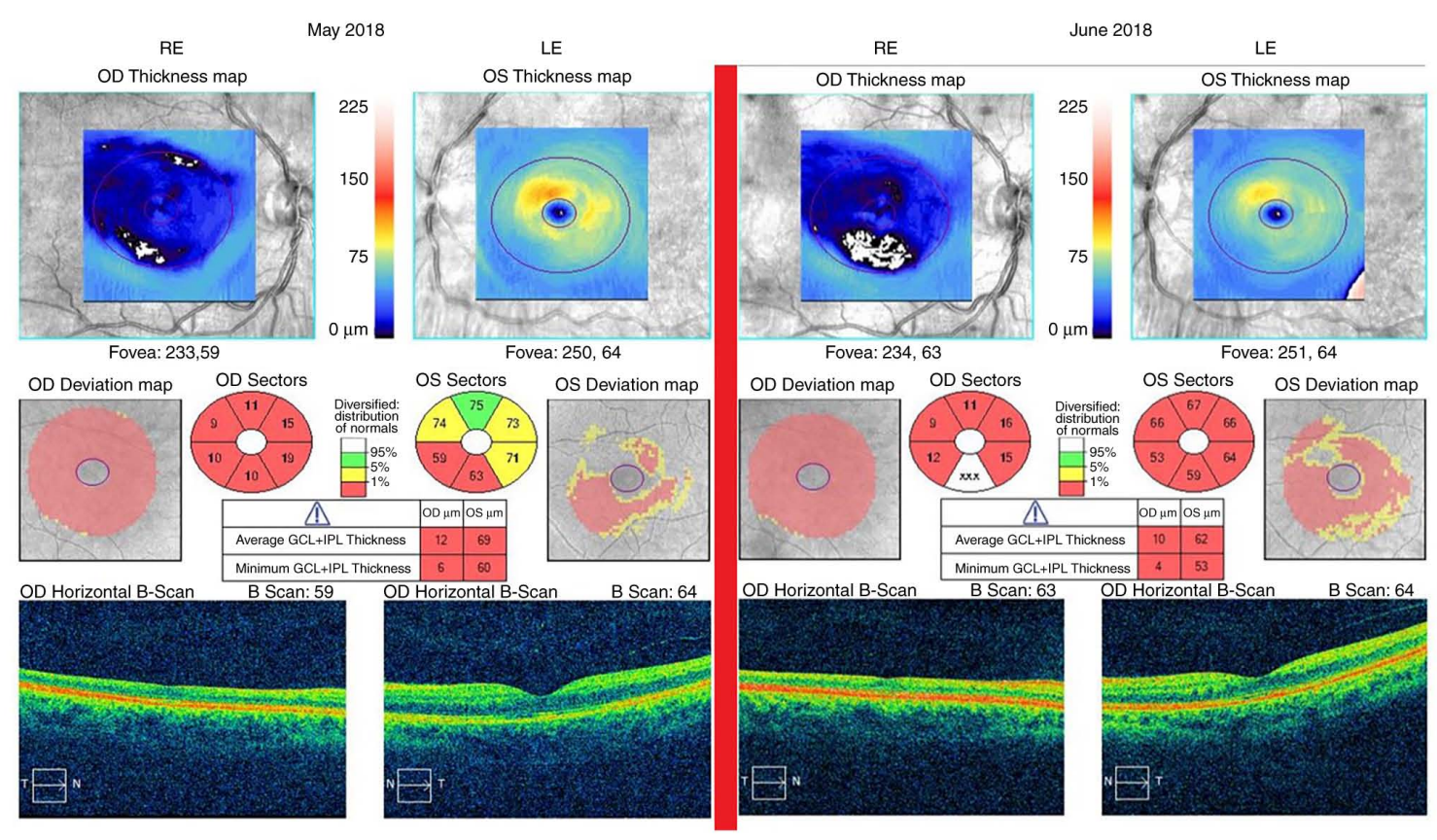

Figure 11. Ganglion cell layer atrophy.

and factor VII up to $1000 \%$. The platelet count decreases up to $20 \%$ and protein S and factor XIII can decrease up to $50 \%$ (36-46). The total of all these changes leads to roughly double the coagulation activity seen when compared with the non-pregnant state, thus causing pregnancy to be a hypercoagulable state (37).

DFS70, a type of anti-nuclear antigen was strongly positive for this patient. Some studies described an immune procoagulant state involving anti-DFS70 antibodies (47). However, this antigen, associated with various diseases, like atopic dermatitis (48), alopecia areata (49) and Vogt-Harada syndrome (50), is positive in $6 \%$ of healthy people $(51,52)$.

Therefore, the hypercoagulable state caused by the pregnancy acted as a precipitating factor on an organism that already had two genetic mutations predisposing to vascular occlusions. After this incident, more specific paraclinical investigations were recommended, which led to the discovery of the Methylenetetrahydrofolate Reductase and Janus Kinase 2 gene mutations.

The visual short-term prognosis for the left eye is good, with complete central visual acuity regain. The visual acuity of the right eye with severe macular atrophy will most likely never recover. The long-term prognosis for this case is, however, uncertain. There is a risk of retinal or iris neovascularization as a complication of the vascular occlusion. New retinal artery or vein occlusions could occur and there is also a risk of thrombosis in other areas, like cerebral, pulmonary or renal, due to the general coagulability imbalance. Essential thrombocythemia also has a small probability to progress towards myelofibrosis and acute leukemia, which may be influenced by the treatment modalities used (36).

The visual and systemic impact of chronic hypercoagulability states is significant. Since they affect patients at a relatively young age, the quality of life is reduced at an active stage of life. Treatment is mandatory, but disease control is not always acquired, and the long-term prognosis varies according to etiology and the presence of additional risk factors.

\section{Acknowledgements}

Professional editing, linguistic and technical assistance performed by Irina Radu, Individual Service Provider, certified translator in Medicine and Pharmacy (certificate credentials: Series E no. 0048).

\section{Funding}

No funding was received.

\section{Availability of data and materials}

All data and materials supporting the results of the present case are available in the published article.

\section{Authors' contributions}

HTS contributed to the conception and design of the study, the acquisition, analysis and interpretation of data of the study. He also contributed to the drafting of the work and its critical revision for important intellectual content. BT contributed to the acquisition, the analysis and interpretation of data of the study, to the drafting of the work and its critical revision for important intellectual content. SS and MMa contributed to the conception and design of the study, the acquisition, analysis and interpretation of data of the study, contributed to the drafting of the work and its critical revision for important intellectual content. $\mathrm{MMu}$, FB, CR and DMD contributed to the conception and design of the study, to the drafting of the work and its critical revision for important intellectual content. ACT contributed to the analysis and interpretation of data of the study, to the drafting of the 
work and its critical revision for important intellectual content All authors read and approved the final version of the manuscript and agreed to be accountable for all aspects of the study in ensuring that questions related to the accuracy or integrity of any part of the work are appropriately investigated and resolved.

\section{Ethics approval and consent to participate}

The study was approved by the Ethics Committee of 'Prof. Dr. Agrippa Ionescu' Emergency Clinical Hospital (approval no., 34/11.06.2018; Bucharest, Romania).

\section{Patient consent for publication}

Written informed consent obtained from the patient prior to publication.

\section{Competing interests}

The authors declare that they have no competing interests.

\section{References}

1. Joussen AM, Gardner TW, Kirchhof B and Ryan SJ (eds): Retinal vascular disease. Section III, Ch. 21, Retinal Artery Occlusion, pp507-518, 2007.

2. Brown GC and Magargal LE: Central retinal artery obstruction and visual acuity. Ophthalmology 89: 14-19, 1982.

3. Landa E, Rehany U and Rumelt S: Visual functions following recovery from non-arteritic central retinal artery occlusion. Ophthalmic Surg Lasers Imaging 35: 103-108, 2004.

4. Stanca HT, Petrović Z and Munteanu M: Transluminal Nd: YAG laser Embolysis - a reasonable method to reperfuse occluded branch retinal arteries. Vojnosanit Pregl 71: 1072-1077, 2014.

5. Arruga J and Sanders MD: Ophthalmologic findings in 70 patients with evidence of retinal embolism. Ophthalmology 89 : 1336-13347, 1982.

6. Mitchell P, Wang JJ and Smith W: Risk factors and significance of finding asymptomatic retinal emboli. Clin Exp Ophthalmol 28: $13-17,2000$.

7. Stanca HT, Suvac E, Munteanu M, Jianu DC, Motoc AGM, Roşca GC and Boruga O: Giant cell arteritis with arteritic anterior ischemic optic neuropathy. Rom J Morphol Embryol 58: 281-285, 2017

8. Braunstein RA and Gass JD: Branch artery obstruction caused by acute toxoplasmosis. Arch Ophthalmol 98: 512-513, 1980.

9. Cohen SM, Davis JL and Gass DM: Branch retinal arterial occlusions in multifocal retinitis with optic nerve oedema. Arch Ophthalmol 113: 1271-1276, 1995.

10. Lightman DA and Brod RD: Branch retinal artery occlusion associated with Lyme disease. Arch Ophthalmol 109: 1198-1199, 1991.

11. Solley WA, Martin DF, Newman NJ, King R, Callanan DG, Zacchei T, Wallace T, Parks DJ, Bridges W and Sternberg P Jr: Cat scratch disease: Posterior segment manifestations. Ophthalmology 106: 1546-1553, 1999.

12. Yokoi M and Kase M: Retinal vasculitis due to secondary syphilis. Jpn J Ophthalmol 48: 65-67, 2004.

13. Klein ML, Jampol LM, Condon PI, Rice TA and Serjeant GR: Central retinal artery occlusion without retrobulbar hemorrhage after retrobulbar anesthesia. Am J Ophthalmol 93: 573-577, 1982.

14. Newman NJ, Lessell S and Brandt EM: Bilateral central retinal artery occlusions, disk drusen, and migraine. Am J Ophthalmol 107: 236-240, 1989.

15. Wallace RT, Brown GC, Benson W and Sivalingham A: Sudden retinal manifestations of intranasal cocaine and methamphetamine abuse. Am J Ophthalmol 114: 158-160, 1992.

16. Joussen AM, Gardner TW, Kirchhof B and Ryan SJ (eds): Retinal vascular disease. Section III, Ch. 21, Central Retinal Vein Occlusion, pp443-461, 2007.

17. Hayreh SS, Zimmerman MB and Podhajsky P: Incidence of various types of retinal vein occlusion and their recurrence and demographic characteristics. Am J Ophthalmol 117: 429-441, 1994.
18. Fong A, Schatz H, McDonald HR, Burton TC, Maberley AL, Joffe L, Zegarra H, Nadel AJ and Johnson RN: Central retinal vein occlusion in young adults (papillophlebitis). Retina 11: 3-11, 1991.

19. Golub BM, Sibony PA and Coller BS: Protein S deficiency associated with central retinal artery occlusion. Arch Ophthalmol 108: 918, 1990.

20. Nelson ME, Talbot JF and Preston FE: Recurrent multiple-branch retinal arteriolar occlusions in a patient with protein $\mathrm{C}$ deficiency. Graefes Arch Clin Exp Ophthalmol 227: 443-447, 1989.

21. Weger M, Renner W, Pinter O, Stanger O, Temmel W, Fellner P, Schmut $\mathrm{O}$ and Haas A: Role of factor V Leiden and prothrombin $20210 \mathrm{~A}$ in patients with retinal artery occlusion. Eye (Lond) 17: 731-734, 2003.

22. Cobo-Soriano R, Sanchez-Ramon S, Aparicio MJ, Teijeiro MA, Vidal P, Suarez-Leoz M, Rodriguez-Mahou M, Rodriguez-Huerta A, Fernández-Cruz E and Cortés C: Antiphospholipid antibodies and retinal thrombosis in patients without risk factors: A prospective case-control study. Am J Ophthalmol 128: 725-732, 1999.

23. Cahill M, Karabatzaki M, Meleady R, Refsum H, Ueland P, Shields D, Mooney D and Graham I: Raised plasma homocysteine as a risk factor for retinal vascular occlusive disease. $\mathrm{Br}$ J Ophthalmol 84: 154-157, 2000.

24. PiankaP,Almog Y,Man O, Goldstein M,Sela BA and Loewenstein A: Hyperhomocystinemia in patients with nonarteritic anterior ischemic optic neuropathy, central retinal artery occlusion, and central retinal vein occlusion. Ophthalmology 107: 1588-1592, 2000.

25. Dean L: Methylenetetrahydrofolate Reductase Deficiency. Mar 8, 2012 [Updated 2016 Oct 27]. In: Pratt VM, McLeod HL, Rubinstein WS, et al (eds). Medical Genetics Summaries [Internet]. Bethesda (MD), National Center for Biotechnology Information (US), 2012. Available from https://www.ncbi.nlm nih.gov/books/NBK66131/. Accessed on July 10, 2020.

26. Humphrey LL, Fu R, Rogers K, Freeman M and Helfand M: Homocysteine level and coronary heart disease incidence: A systematic review and Meta-analysis. Mayo Clin Proc 83: 1203-1212, 2008.

27. den Heijer M, Rosendaal FR, Blom HJ, Gerrits WB and Bos GM: Hyperhomocysteinemia and venous thrombosis: A meta-analysis. Thromb Haemost 80: 874-877, 1998.

28. Kupferminc MJ, Eldor A, Steinman N, Many A, Bar-Am A, Jaffa A, Fait G and Lessing JB: Increased frequency of genetic thrombophilia in women with complications of pregnancy. $\mathrm{N}$ Engl J Med 340: 9-13, 1999.

29. McLornan D, Percy M and McMullin MF: JAK2 V617F: A single mutation in the myeloproliferative group of disorders. Ulster Med J 75: 112-119, 2006.

30. Jackson TL and Moorfields Eye Hospital: Moorfields Manual of Ophthalmology. Philadelphia, PA, Mosby Elsevier, 2008.

31. Munteanu M, Rosca C and Stanca HT: Sub-inner limiting membrane hemorrhage in a patient with Terson syndrome. Int Ophthalmol 39: 461-464, 2019.

32. Holmes MV, Newcombe P, Hubacek JA, Sofat R, Ricketts SL, Cooper J, Breteler MM, Bautista LE, Sharma P, Whittaker JC, et al: Effect modification by population dietary folate on the association between MTHFR genotype, homocysteine, and stroke risk: A meta-analysis of genetic studies and randomised trials. Lancet 378: 584-594, 2011.

33. Shiran A, Remer E, Asmer I, Karkabi B, Zittan E, Cassel A, Barak M, Rozenberg O, Karkabi K and Flugelman MY: Association of vitamin B12 deficiency with homozygosity of the TT MTHFR C677T genotype, hyperhomocysteinemia, and endothelial cell dysfunction. Isr Med Assoc J 17: 288-292, 2015.

34. van der Put NM, Gabreels F, Stevens EM, Smeitink JA, Trijbels FJ, Eskes TK, van den Heuvel LP and Blom HJ: A second common mutation in the methylenetetrahydrofolate reductase gene: An additional risk factor for neural-tube defects? Am J Hum Genet 62: 1044-1051, 1998.

35. Clarke R, Bennett DA, Parish S, Verhoef P, Dötsch-Klerk M, Lathrop M, Xu P, Nordestgaard BG, Holm H, Hopewell JC, et al: Homocysteine and coronary heart disease: Meta-analysis of MTHFR case-control studies, avoiding publication bias. PLoS Med 9: e1001177, 2012.

36. Campbell PJ, Scott LM, Buck G, Wheatley K, East CL, Marsden JT, Duffy A, Boyd EM, Bench AJ, Scott MA, et al: United kingdom myeloproliferative disorders study group; Medical research council adult leukaemia working party; Australasian leukaemia and lymphoma group definition of subtypes of essential thrombocythaemia and relation to polycythaemia vera based on JAK2 V617F mutation status: A prospective study. Lancet 366: 1945-1953, 2005. 
37. Katz $\mathrm{D}$ and Beilin Y: Disorders of coagulation in pregnancy. $\mathrm{Br}$ J Anaesth 115 (Suppl 2): ii75-ii88, 2015.

38. Brenner B: Haemostatic changes in pregnancy. Thromb Res 114: 409-414, 2004.

39. James AH: Pregnancy and thrombotic risk. Crit Care Med 38 (Suppl 2): S57-S63, 2010.

40. Abbassi-Ghanavati M, Greer LG and Cunningham FG: Pregnancy and laboratory studies: A reference table for clinicians. Obstet Gynecol 114: 1326-1331, 2009.

41. Cerneca F, Ricci G, Simeone R, Malisano M, Alberico S and Guaschino S: Coagulation and fibrinolysis changes in normal pregnancy. Increased levels of procoagulants and reduced levels of inhibitors during pregnancy induce a hypercoagulable state, combined with a reactive fibrinolysis. Eur J Obstet Gynecol Reprod Biol 73: 31-36, 1997.

42. Prisco D, Ciuti G and Falciani M: Hemostatic changes in normal pregnancy. Hematol Meet Reports (Formerly Haematol Reports) 1: 1-5, 2005.

43. O'Riordan MN and Higgins JR: Haemostasis in normal and abnormal pregnancy. Best Pract Res Clin Obstet Gynaecol 17: 385-396, 2003.

44. Bremme K, Ostlund E, Almqvist I, Heinonen K and Blombäck M: Enhanced thrombin generation and fibrinolytic activity in normal pregnancy and the puerperium. Obstet Gynecol 80: 132-137, 1992.

45. Szecsi PB, Jørgensen M, Klajnbard A, Andersen MR, Colov NP and Stender S: Haemostatic reference intervals in pregnancy. Thromb Haemost 103: 718-727, 2010.

46. Comp PC, Thurnau GR, Welsh J and Esmon CT: Functional and immunologic protein $\mathrm{S}$ levels are decreased during pregnancy. Blood 68: 881-885, 1986.
47. Marlet J, Ankri A, Charuel JL, Ghillani-Dalbin P, Perret A, Martin-Toutain I, Haroche J, Amoura Z, Musset L and Miyara M: Thrombophilia associated with anti-DFS70 autoantibodies. PLoS One 10: e0138671, 2015.

48. Ochs RL,Muro Y,Si Y, GeH,Chan EK and Tan EM: Autoantibodies to DFS $70 \mathrm{kd} /$ transcription coactivator $\mathrm{p} 75$ in atopic dermatitis and other conditions. J Allergy Clin Immunol 105: 1211-1220, 2000.

49. Okamoto M, Ogawa Y, Watanabe A, Sugiura K, Shimomura Y, Aoki N, Nagasaka T, Tomita Y and Muro Y: Autoantibodies to DFS70/LEDGF are increased in alopecia areata patients. J Autoimmun 23: 257-266, 2004.

50. Shinohara T, Singh DP and Chylack LT Jr: Review: Age-related cataract: Immunity and lens epithelium-derived growth factor (LEDGF). J Ocul Pharmacol Ther 16: 181-191, 2000.

51. Yamada K, Senju S, Shinohara T, Nakatsura T, Murata Y, Ishihara M, Nakamura S, Ohno S, Negi A and Nishimura Y: Humoral immune response directed against LEDGF in patients with VKH. Immunol Lett 78: 161-168, 2001.

52. Watanabe A, Kodera M, Sugiura K, Usuda T, Tan EM, Takasaki Y, Tomita Y and Muro Y: Anti-DFS70 antibodies in 597 healthy hospital workers. Arthritis Rheum 50: 892-900, 2004. Attribution-NonCommercial-NoDerivatives 4.0 International (CC BY-NC-ND 4.0) License. 